\title{
Geographic variations of the prevalence and distribution of COPD phenotypes in Spain: "the ESPIRAL-ES study"
}

This article was published in the following Dove Press journal: International Journal of COPD

\section{Bernardino Alcázar- Navarrete' Juan Antonio Trigueros ${ }^{2}$ Juan Antonio Riesco ${ }^{3,4}$ Anna Campuzano ${ }^{5}$ Joselín Pérez ${ }^{5}$}

'Pulmonology Department, Hospital La Loja, Granada, ${ }^{2}$ Centro de Salud de Menasalvas, Toledo, ${ }^{3}$ Pulmonology Department, Hospital San Pedro de Alcántara, ${ }^{4}$ Centro de Investigación en Red de Enfermedades Respiratorias (CIBERES), Cáceres, ${ }^{5}$ Grupo Ferrer Internacional, Barcelona, Spain
Correspondence: Bernardino Alcázar-Navarrete AIG de Medicina, Hospital de Alta Resolución de Loja, Agencia Sanitaria Hospital de Poniente, Avda Tierno Galván s/n, Loja 18300, Granada, Spain Tel +34958338 I30

Fax +34958338I57

Email balcazar@telefonica.net
Purpose: The purpose of this study was to assess the prevalence of COPD phenotypes at a national level and to determine their geographic distribution among different autonomous communities in Spain.

Patients and methods: A total of 1,610 patients ( $82 \%$ men, median age 67 years) recruited in primary care centers and pneumology services participated in an observational, crosssectional, and multicenter study. Phenotypes evaluated were the non-exacerbator phenotype, the asthma-COPD overlap syndrome (ACOS), the exacerbator phenotype with emphysema, and the exacerbator phenotype with chronic bronchitis.

Results: The non-exacerbator phenotype was the most common (46.7\%) followed by exacerbator with chronic bronchitis (22.4\%) and exacerbator with emphysema (16.4\%). The ACOS phenotype accounted for the lowest rate (14.5\%). For each phenotype, the highest prevalence rates were concentrated in two or three autonomous communities, with relatively similar rates for the remaining regions. Overall prevalence rates were higher for the non-exacerbator and the exacerbator with chronic bronchitis phenotypes than for ACOS and the exacerbator with chronic bronchitis phenotypes. Differences in the distribution of COPD phenotypes according to gender, age, physician specialty, smoking habit, number of comorbidities, quality of life assessed with the COPD Assessment Test, and BODEx index (body mass index, airflow obstruction, dyspnea, and exacerbations) were all statistically significant.

Conclusion: Differences in the prevalence rates of COPD phenotypes among the Spanish autonomous communities have been documented. Mapping the distribution of COPD phenotypes is useful to highlight regional differences as starting point for comparisons across time. This geographic analysis provides health-care planners a valuable platform to assess changes in COPD burden at nationwide and regional levels.

Keywords: pulmonary disease, chronic obstructive, phenotype, quality of life

\section{Introduction}

COPD is a preventable and treatable disease that causes heavy cost on health and is an economic burden around the world. Globally, the prevalence and morbimortality of COPD are still increasing partly due to the increasing age of the world's population, the continued smoking of tobacco, and the effect of biomass exposure in low-income countries. ${ }^{1,2}$ In the Global Burden of Disease Study, COPD ranked the eleventh position among the top 30 causes of years lived with disability (YLD), largely affecting the elderly and is expected to become a prominent cause of YLDs in an aging global population. ${ }^{3}$ Data for Spain showed that COPD was the tenth leading cause of disabilityadjusted life years, which was consistent with findings reported for other high-income 
countries. ${ }^{4}$ Epidemiological studies have shown a prevalence of COPD of $9.1 \%$ in the Spanish general population aged between 40 and 69 years $^{5}$ and of $10.2 \%$ in the population aged between 40 and 80 years. $^{6}$

The disease impacts patients through progressive and irreversible airflow obstruction and reduced quality of life. As the disease advances, symptoms worsen, exacerbations increase in frequency and severity, and lung function is further compromised causing a downward spiral of events that may progressively lead to death. ${ }^{7}$ Moreover, many subjects with COPD are frequently misdiagnosed or undiagnosed. Failure to use spirometry for diagnosis has been recognized as an important factor associated with underdiagnosis of COPD. ${ }^{8}$ Also, significant heterogeneity of clinical presentation and disease progression exists within COPD, with $\mathrm{FEV}_{1}$ inadequately describing this heterogeneity. ${ }^{9}$

The introduction of different alternatives of pharmacological and non-pharmacological treatments has shown that the patient's clinical response can be different according to the characteristic of the disease. The concept of phenotype, defined as "a single or single or combination of disease attributes that describe differences between individuals with COPD as they relate to clinically meaningful outcomes," 10 has resulted in the definition of different types of patients with prognostic and therapeutic significance. ${ }^{11}$ In Spain, the guidelines for COPD (GesCOPD) published by the Spanish Society of Pulmonology and Thoracic Surgery ${ }^{11}$ proposed four phenotypes, each with a different prognosis and therapeutic approach: the non-exacerbator phenotype (with emphysema or chronic bronchitis), the asthma-COPD overlap syndrome (ACOS), the exacerbator phenotype with emphysema, and the exacerbator phenotype with chronic bronchitis.

The increasing acceptance toward a phenotype-driven therapeutic approach in patients with COPD has prompted a renewed interest to assess the prevalence of different COPD phenotypes in populations at large. In this respect, the POPE study has been designed to gain a better understanding of these phenotypic characteristics and treatment patterns of patients diagnosed with COPD among different central and eastern European countries. ${ }^{12}$ In a recent epidemiological study carried out in Spain, in which 647 patients with COPD were recruited in primary care and pulmonology centers, the non-exacerbator phenotype was the most frequent $(47.5 \%)$ followed by exacerbator with chronic bronchitis (29.1\%), exacerbator with emphysema (17.0\%), and ACOS (6.5\%). ${ }^{13}$ However, in this pioneering study of COPD phenotype distribution, geographic variations regarding the prevalence phenotypes all over the country were not assessed.
The primary objective of this study was to determine the prevalence and the geographic distribution of the COPD phenotypes in Spain and to assess whether there were differences in the prevalence and clinical characteristics among the various territorial regions constituted as 17 autonomous communities.

ESPIRAL-ES is the Spanish acronym for Study of the Prevalence of COPD phenotypes, assessment of health-related quality, and geographic distribution in Spain ("EStudio de la Prevalencia de los fenotIpos de la EPOC, valoRación de la cALidad de vida relacionada con la salud y su distribución geográfica en España”).

\section{Patients and methods Study design and organization}

This was an observational, cross-sectional, multicenter study performed in primary care centers and pneumology services throughout Spain. The primary objective of the study was to determine the prevalence and geographic distribution of the four COPD phenotypes established by GesCOPD ${ }^{11}$ in Spain, in particular, to evaluate whether there were differences in the prevalence of these phenotypes among different autonomous regions of the country. The secondary objectives were to assess whether there were differences in severity and impact on health-related quality of life in relation to the four phenotypes. The study was approved by the Ethics Committee of the Hospital San Pedro de Alcántara, Cáceres, Spain. All participants provided written informed consent.

The sample population included patients diagnosed with COPD visited by family/community medicine specialists and pulmonologists in routine daily practice. Recruitment was prospective, whereby the first two to four patients with a diagnosis of COPD who attended primary care and pulmonology services for a routine clinical visit and met the inclusion criteria were consecutively included in the study. A 90-day recruitment period, between March and May 2015, was established.

Assuming an expected prevalence of COPD of $10.2 \%$ in the Spanish general population aged 40-80 years previously reported in the EPI-SCAN study, ${ }^{6}$ with a precision of $3.1 \%$ at national level ( $7.29 \%$ at autonomous community level) and $38 \%$ in a bilateral contrast, with an alpha risk of $5 \%$ assuming maximal variability ( $p=50 \%, q=505)$ and with $5 \%$ of losses, a total sample of 1,050 patients would be required to fulfill the primary goal of the study. Therefore, for an expected recruitment of two to four patients per physician, a minimum of 262 and a maximum of 525 participating researchers would be necessary. In addition, with a sample of 350 physicians, it will be possible to assess whether clinicians were aware 
and treated patients according to COPD phenotypes, with a precision of $5.4 \%$ at national level in a bilateral contrast, an alpha risk of $5 \%$ and assuming $5 \%$ of losses.

Participating physicians were selected using a commercially available database (www.medynet.com). A stratified random sampling method based on population size of each autonomous community was used (except La Rioja region, which represents $0.68 \%$ of the total population in Spain), leaving a total of 16 autonomous communities. Physicians were recruited by email with successive email contacts until the target number of participants was achieved.

\section{Selection criteria and study procedures}

Patients were included in the study if they were over the age of 35 years and have a clinical and functional diagnosis of COPD according to Global Initiative for Chronic Obstructive Lung Disease (GOLD) ${ }^{13}$ or GesEPOC ${ }^{14}$ criteria at least 6 months before enrollment in the study. Patients with symptoms of COPD exacerbation or who had an exacerbation within the previous 6 months were excluded as were patients with any type of chronic respiratory disease other than COPD or asthma, or patients with cognitive difficulties for reading and understanding the study questionnaires.

Each investigator used a case report form to collect sociodemographic data and clinical variables for each patient. Sociodemographic variables were age, gender, duration of COPD, education level, and working status. Clinical variables included anthropometric data, smoking habit, spirometry results in the previous 12 months, degree of dyspnea assessed with the modified Medical Research Council scale, ${ }^{15}$ the 6 -minute walking distance test, number of severe exacerbations in the previous 12 months defined as episodes that required admission to the hospital, or stay in an emergency department for more than 24 hours, comorbidities (hypertension, diabetes mellitus, arrhythmia, coronary artery disease, heart failure, osteoporosis, dyslipidemia, and dementia), COPD severity using the BODEx index ${ }^{16}$ (quartile 1, 0-2 points; quartile 2, 3-4 points, quartile 3, 5-6 points, quartile $4, \geq 7$ points), and quality of life using the COPD assessment test (CAT). ${ }^{17}$ The range of CA scores in $0-40$ and higher scores indicate a more severe impact of COPD on the patient's health-related quality of life.

To determine COPD phenotype, the GesCOPD algorithm ${ }^{14}$ was used. This algorithm classifies the phenotype according to the following rules: 1 ) patients with $<2$ exacerbations in the previous year were classified as non-exacerbators; 2) patients with a previous diagnosis of asthma were considered as ACOS; 3 ) exacerbators with emphysema that have a clinical/radiological/functional diagnosis of emphysema; and 4) exacerbators who experienced cough with expectoration for $>3$ months of the year over 2 consecutive years were classified as exacerbators with chronic bronchitis. Exacerbators were considered in the presence of two or more moderate or severe exacerbations in the previous 12 months. ${ }^{14}$ ACOS was diagnosed when two major criteria and two minor criteria are met. ${ }^{18}$ The major criteria included very positive bronchodilator test (increase in $\mathrm{FEV}_{1} \geq 15 \%$ and $\geq 400 \mathrm{~mL}$ ), eosinophilia in sputum, and personal history of asthma; minor criteria included high total $\mathrm{IgE}$, personal history of atopy, and positive bronchodilator test (increase in $\mathrm{FEV}_{1} \geq 12 \%$ and $\geq 200 \mathrm{~mL}$ ) on two or more occasions. ${ }^{18}$ The schematic algorithm was provided to all participating physicians.

\section{Statistical analysis}

Data were expressed as mean and SD for continuous variables and absolute and relative frequencies (percentages) for categorical variables, with their 95\% CI. Categorical variables were compared with the chi-square $\left(\chi^{2}\right)$ test or the Fisher's exact test and continuous variables with the Student's $t$-test or the analysis of variance for values with a normal distribution, and the Mann-Whitney $U$ test or the Kruskal-Wallis test for data whose distribution departed from normality. Statistical significance was set at $p<0.05$. The statistical analysis systems (SAS Institute, Cary, NC, USA) statistical software package, version 9.4 for Windows was used for all analyses.

\section{Results}

A total of 563 physicians participated in the study $(55.8 \%$ pneumologists, $39.9 \%$ family/community medicine specialists, $7.1 \%$ internists, and $0.2 \%$ occupational medicine specialists) with a median age of 48 years (interquartile range: 36-58), 52\% men and a median time since graduation of 22 years. They recruited a total of 1,680 patients but $70(4.2 \%)$ were excluded (age $<35$ years in one patient, symptoms of exacerbation in the past 6 weeks in 58, and exclusion criteria not recorded in 11). Therefore, data of 1,610 patients were included in the analysis. The main characteristics of the study population are shown in Table 1. Salient features included a very high percentage of men $(82.3 \%)$, mean age of 66.7 years, overweight with a mean body mass index (BMI) of $27.0 \mathrm{~kg} / \mathrm{m}^{2}, 64.8 \%$ of patients with secondary education or university studies, $58 \%$ of retired persons, and $55.4 \%$ of patients who stated they were active smokers, with a smoking index of 65.0 pack-years and a mean $\mathrm{FEV}_{1}$ of $54.7 \%$. The mean (SD) years from COPD diagnosis was 8.9 (7.9) years. Also, comorbidities were present in $83.8 \%$ of patients, with hypertension (60.5\%), dyslipidemia (53.5\%), and diabetes 
Table I Characteristics of the study population

\begin{tabular}{|c|c|c|}
\hline Study variables & $\begin{array}{l}\text { Number of } \\
\text { valid data }\end{array}$ & Total population \\
\hline Sex & 1,600 & \\
\hline Male & & $1,314(82.3)$ \\
\hline Female & & $286(17.9)$ \\
\hline Age, years, mean $(\mathrm{SD})[95 \% \mathrm{Cl}]$ & 1,580 & $66.7(9.7)[66.2-67.2]$ \\
\hline Body mass index, $\mathrm{kg} / \mathrm{m}^{2}$, mean (SD) $[95 \% \mathrm{Cl}]$ & $1,58 \mid$ & $27.9 \pm 4.7(27.6-28.1)$ \\
\hline Smoking status & 1,608 & \\
\hline Current smoker & & $891(55.4)$ \\
\hline Ex-smoker & & $677(39.7)$ \\
\hline Never smoker & & $40(2.5)$ \\
\hline Smoking index, pack-years, mean (SD) $[95 \% \mathrm{Cl}]$ & 849 & $65.0(94.9)[58.2-71.4]$ \\
\hline Years from COPD diagnosis, mean (SD) $[95 \% \mathrm{Cl}]$ & 1,505 & $8.9(7.9)[8.5-9.3]$ \\
\hline Comorbidities & 1,610 & \\
\hline Yes & & $1,349(83.8)$ \\
\hline No & & $261(16.2)$ \\
\hline Number of comorbidities, mean (SD) $[95 \% \mathrm{Cl}]$ & & $2.0(1.4)[1.4-1.9]$ \\
\hline \multicolumn{3}{|l|}{ Spirometry, mean (SD) $[95 \% \mathrm{Cl}]$} \\
\hline $\mathrm{FVC}, \mathrm{mL}$ & 1,234 & $2,499.9(869.4)[2,451.4-2,548.5]$ \\
\hline FVC, \% & I,329 & 73.5 (14.4) [72.7-74.2] \\
\hline $\mathrm{FEV}_{1}, \mathrm{~mL}$ & 1,236 & $1,350(55 \mid .9)[1,319.3-1,380.5]$ \\
\hline $\mathrm{FEV}_{1}, \%$ & 1,345 & 54.7 (15.1) [53.9-55.5] \\
\hline FVC/FEV, & 1,358 & $55.4(12.2)[54.7-56.0]$ \\
\hline Dyspnea & 1,594 & \\
\hline Grade 0 & & $98(6.1)$ \\
\hline Grade I & & $572(35.9)$ \\
\hline Grade 2 & & $565(35.4)$ \\
\hline Grade 3 & & $318(19.9)$ \\
\hline Grade 4 & & $4 \mid(2.6)$ \\
\hline 6-minute walking test, $\mathrm{m}$ & 1,009 & \\
\hline$\geq 350$ & & $405(40.1)$ \\
\hline $250-349$ & & $315(31.2)$ \\
\hline $150-249$ & & $200(19.8)$ \\
\hline$<149$ & & $89(8.8)$ \\
\hline Severe exacerbations in previous year, mean (SD) $[95 \% \mathrm{Cl}]$ & 1,567 & $0.9(1.2)[0.9-1.0]$ \\
\hline Two or more moderate-severe exacerbations & 1,603 & $672(41.9)$ \\
\hline CAT score, mean (SD) $[95 \% \mathrm{Cl}]$ & 1,591 & $20.9(8.9)[20.4-21.3]$ \\
\hline COPD impact according to CAT & 1,591 & \\
\hline None, score $<5$ & & $55(3.5)$ \\
\hline Low, score 5-9 & & $128(8.0)$ \\
\hline Medium, score 10-20 & & $559(35.1)$ \\
\hline High, score $>20$ & & $614(38.6)$ \\
\hline Very high, score $>30$ & & $235(14.8)$ \\
\hline BODEx index, mean (SD) $[95 \% \mathrm{Cl}]$ & 1,423 & 2.7 (1.9) [2.6-2.9] \\
\hline $0-2$ points & & $692(48.6)$ \\
\hline $3-4$ points & & $449(31.6)$ \\
\hline $5-6$ points & & $236(16.6)$ \\
\hline$\geq 7$ points & & $46(3.2)$ \\
\hline
\end{tabular}

Note: Data expressed as frequencies and percentages in parenthesis unless otherwise stated.

Abbreviations: FVC, forced vital capacity; $\mathrm{FEV}_{1}$, forced expiratory volume in I second; BODEx, body mass index, airflow obstruction, dyspnea, and exacerbations; CAT, COPD assessment test.

$(28.8 \%)$ as the most frequent. Dyspnea grade $\geq 2$ was recorded in $58 \%$ of patients. In the 6 -minute test, $60 \%$ of patients walked $<350 \mathrm{~m}$. The mean BODEx index was 2.7 and the mean CAT score 20.9.
With regard to phenotype distribution, the non-exacerbator phenotype was the most common (46.7\%) followed by exacerbator with chronic bronchitis $(22.4 \%)$ and exacerbator with emphysema (16.4\%). The ACOS phenotype 


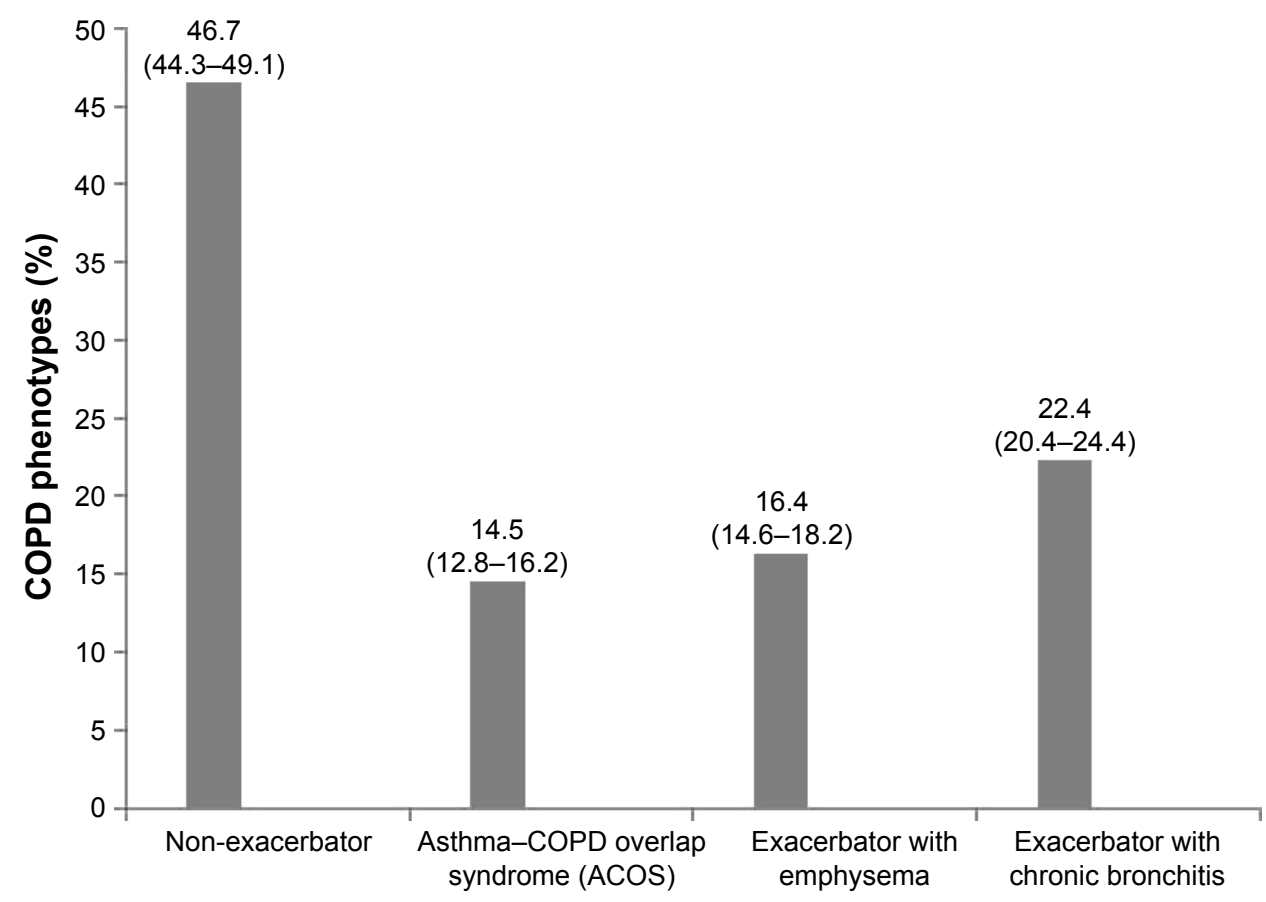

Figure I Overall prevalence of COPD phenotypes in I,610 patients with COPD (percentages and $95 \% \mathrm{Cl}$ in parenthesis).

accounted for the lowest percentage (14.5\%) (Figure 1). The geographic variation of the prevalence rates of the four COPD phenotypes among the different autonomous regions are shown in Figures 2-5. In general, except for the two or three regions with the highest prevalence rates within each phenotype, prevalence rates for the remaining regions were quite uniform. The non-exacerbator phenotype showed the highest prevalence rates throughout the country, with rates between $40 \%$ and $55 \%$ in most of the autonomous communities. The ACOS phenotype showed the lowest overall prevalence as compared with the other three phenotypes, with ranges around $10 \%-15 \%$ in most of the regions. The prevalence rates for the exacerbator with emphysema phenotype were higher as compared with the ACOS phenotype, with an average between $15 \%$ and $20 \%$. The prevalence rates for the exacerbator with chronic bronchitis phenotype were higher as compared with the ACOS and the exacerbator with emphysema phenotype, varying between $20 \%$ and $30 \%$.

Differences in the prevalence of COPD phenotypes in relation to the study variables are summarized in Table 2 . Men showed higher prevalence of non-exacerbator and exacerbator with chronic bronchitis phenotypes as compared with women, in whom ACOS phenotype was more common. Differences in phenotype distribution by gender were statistically significant ( $p=0.002$ ). In relation to age, as age increased, the prevalence rates of the exacerbator phenotypes also increased. The prevalence of the non-exacerbator phenotype was significantly more frequent in the pneumology specialized setting than in primary care $(p<0.001)$. Active smokers were predominantly among the exacerbator phenotypes with emphysema and chronic bronchitis $(57.7 \%$ and $58.9 \%$, respectively, $p=0.03$ ). The mean number of comorbidities was also higher among the exacerbator phenotypes with emphysema and chronic bronchitis (1.45 and 1.48, respectively, $p<0.001$ ). Also, the percentage of patients with more than three comorbidities was particularly high in the exacerbator phenotype with chronic bronchitis (23.2\%). The non-exacerbator phenotype showed the lowest mean CAT score when compared with the remaining phenotypes $(p<0.001)$, and this phenotype was also associated with the lowest impact on CAT $(p<0.001)$. Finally, in relation to the BODEx index, as the BODEx index decreased, the prevalence of exacerbator phenotypes increased, whereas the prevalence of non-exacerbator and ACOS phenotypes decreased $(p<0.001)$.

\section{Discussion}

This was a larger study designed to assess the distribution of COPD phenotypes among patients diagnosed with COPD throughout Spain, in particular, to describe the prevalence of the different phenotypes across the different autonomous communities of the country. COPD patients were recruited in 16 of the 17 Spanish autonomous communities, except La Rioja with $0.68 \%$ of the total population. In this respect, 


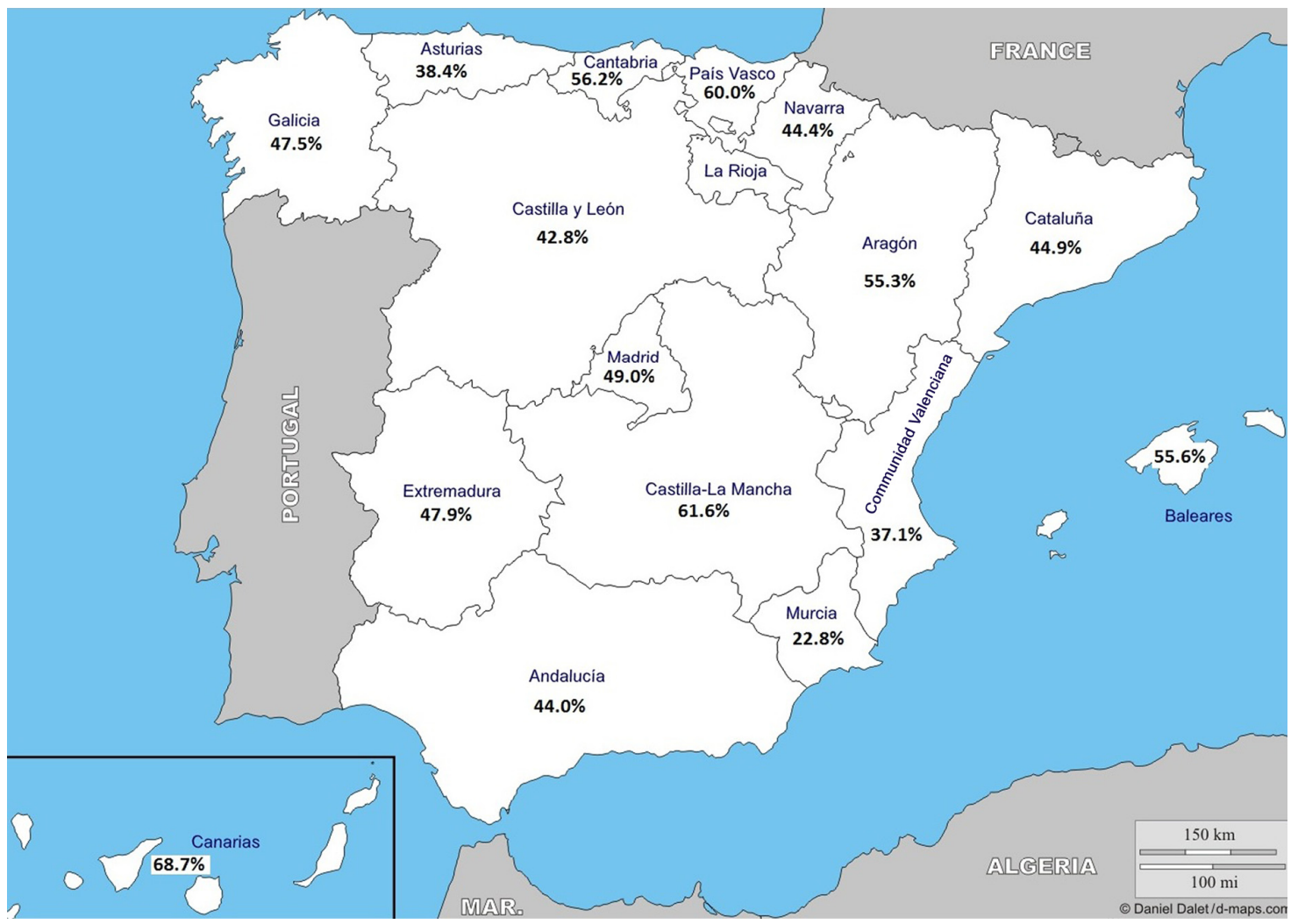

Figure 2 Geographic distribution of the prevalence of the non-exacerbator COPD phenotype showing the highest prevalence rates in the Canary Islands, Castilla-La Mancha, and the Basque Country.

Note: Courtesy of http://d-maps.com/carte.php?num_car=2210\&lang=es.

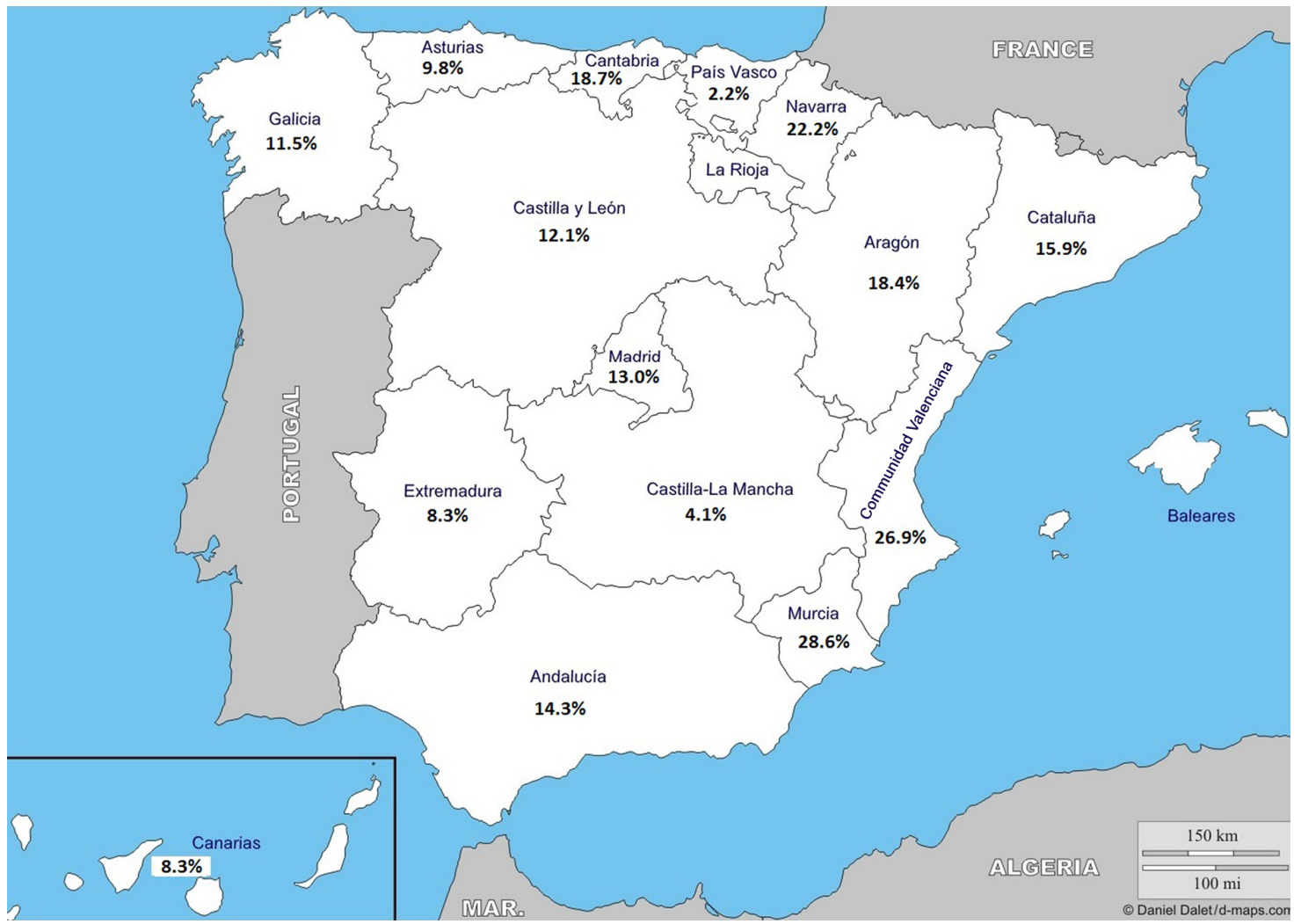

Figure 3 Geographic distribution of the prevalence of the asthma-COPD overlap syndrome (ACOS) phenotype, with Murcia, Valencia, and Navarra showing the highest prevalence rates.

Note: Courtesy of http://d-maps.com/carte.php?num_car=2210\&lang=es. 


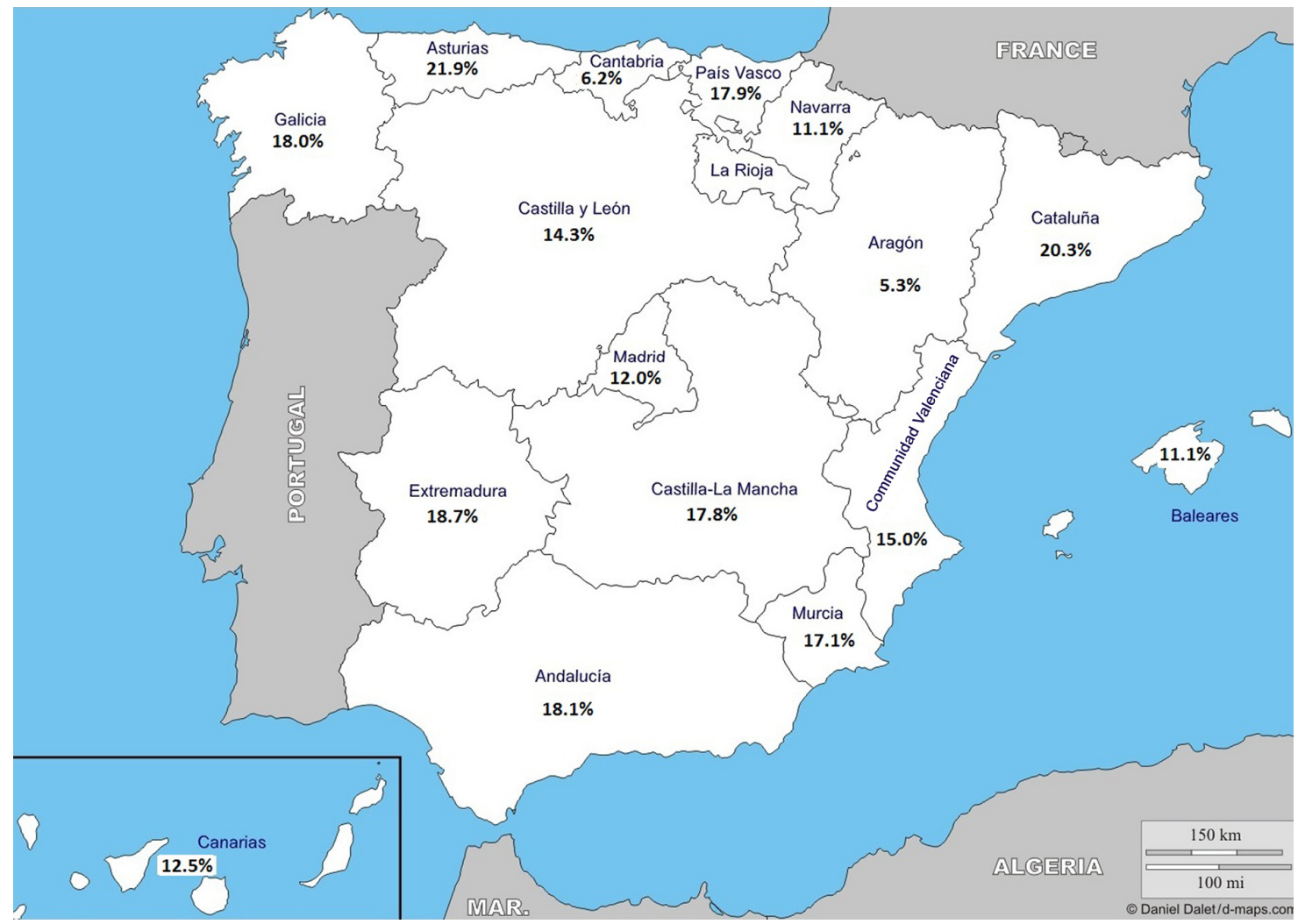

Figure 4 Geographic distribution of the prevalence of the exacerbator phenotype with emphysema. The highest prevalence rate in Asturias followed by Cataluña, Extremadura, and Andalucía.

Note: Courtesy of http://d-maps.com/carte.php?num_car=2210\&lang=es.

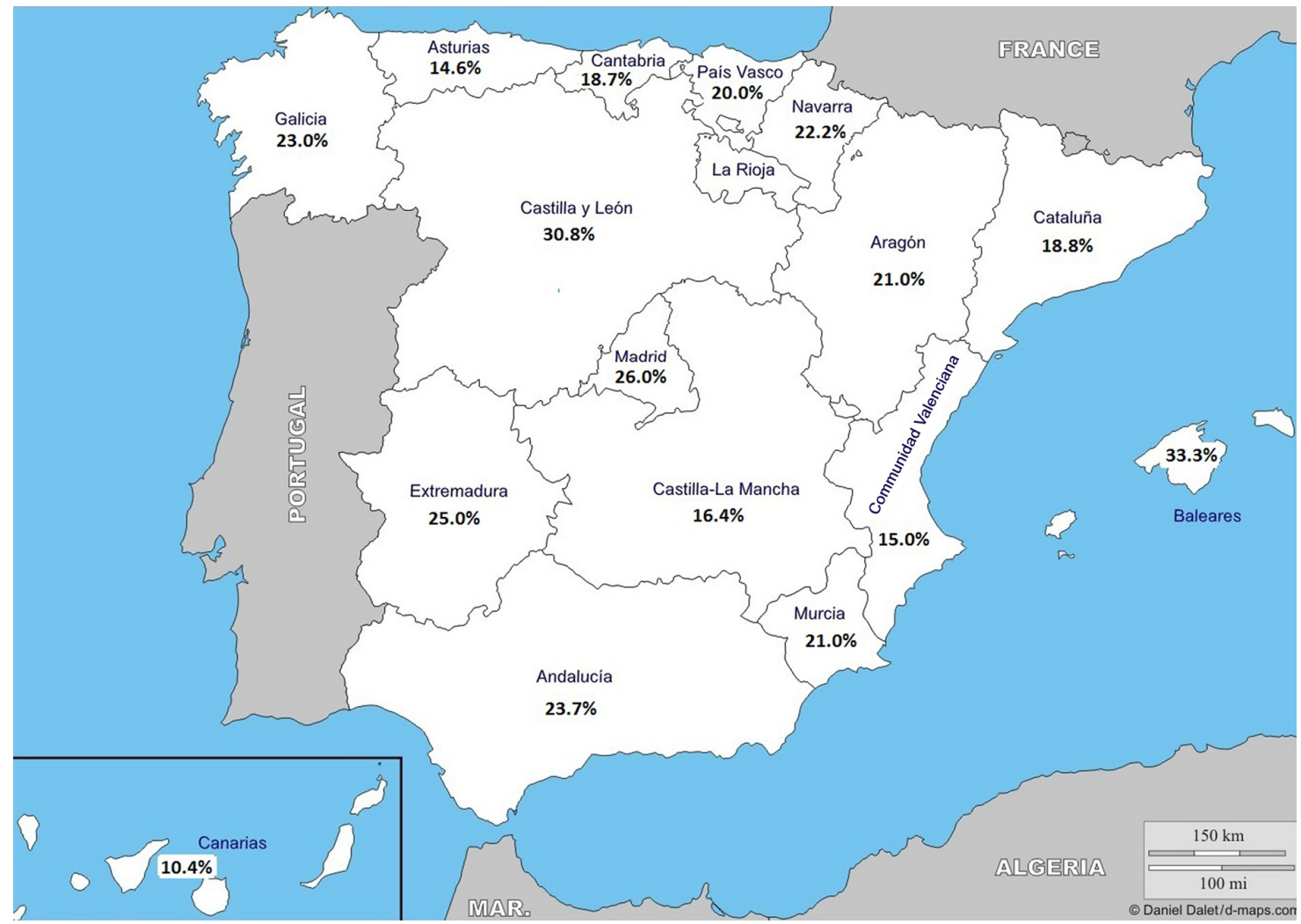

Figure 5 Geographic distribution of the prevalence of the exacerbator phenotype with chronic bronchitis showing the highest prevalence rate in Castilla-León, Balearic Islands, and Madrid.

Note: Courtesy of http://d-maps.com/carte.php?.num_car=2210\&lang=es. 
Table 2 Comparison of COPD phenotypes according to the study variables

\begin{tabular}{|c|c|c|c|c|c|}
\hline \multirow[t]{2}{*}{ Variables } & \multicolumn{4}{|l|}{ COPD phenotypes } & \multirow[t]{2}{*}{$p$-value } \\
\hline & Non-exacerbator & Acos & $\begin{array}{l}\text { Exacerbator } \\
\text { with emphysema }\end{array}$ & $\begin{array}{l}\text { Exacerbator } \\
\text { with chronic } \\
\text { bronchitis }\end{array}$ & \\
\hline \multicolumn{6}{|l|}{ Sex } \\
\hline Male & $618(47.9)$ & $167(12.9)$ & $209(16.2)$ & $296(22.9)$ & 0.002 \\
\hline Female & $117(42.2)$ & $60(21.7)$ & $48(17.3)$ & $52(18.8)$ & \\
\hline \multicolumn{6}{|l|}{ Age, years } \\
\hline $35-60$ & $208(50.5)$ & $77(18.7)$ & $55(13.3)$ & $72(17.5)$ & 0.005 \\
\hline $6 I-65$ & $128(46.5)$ & $4 \mid(\mid 4.9)$ & $48(17.4)$ & $58(21.1)$ & \\
\hline $66-75$ & $245(44.8)$ & $68(12.4)$ & $90(16.4)$ & I 44 (26.3) & \\
\hline$>75$ & I44 (46.I) & $35(1 \mathrm{I} .2)$ & $59(18.9)$ & $74(23.7)$ & \\
\hline \multicolumn{6}{|l|}{ Physician specialty } \\
\hline Primary care & $154(31.8)$ & $105(21.7)$ & $70(14.5)$ & $155(32.0)$ & 0.0001 \\
\hline Pneumology & $448(58.3)$ & $68(8.8)$ & $135(17.6)$ & $118(15.3)$ & \\
\hline \multicolumn{6}{|l|}{ Smoking status } \\
\hline Current smoker & $40 \mathrm{I}(54.6)$ & $112(48.9)$ & $152(58.9)$ & $203(57.7)$ & 0.03 \\
\hline Ex-smoker & $320(43.5)$ & $104(45.4)$ & $102(39.5)$ & $142(40.3)$ & \\
\hline Never smoker & $14(1.9)$ & $13(5.7)$ & $5(1.6)$ & $7(2.0)$ & \\
\hline Comorbidities, mean (SD) & $1.68(1.30)$ & $2.10(1.35)$ & $2.13(1.45)$ & $2.59(1.48)$ & $<0.001$ \\
\hline One & $202(27.4)$ & $38(16.6)$ & $55(21.3)$ & $56(15.7)$ & $<0.00 \mathrm{I}$ \\
\hline Two & $207(28 . I)$ & $74(32.3)$ & $63(24.4)$ & $110(31.2)$ & \\
\hline Three & III (I5.I) & $50(21.8)$ & $58(22.5)$ & $83(23.5)$ & \\
\hline More than three & $65(8.8)$ & $33(14.4)$ & $44(17.1)$ & $82(23.2)$ & \\
\hline CAT score, mean (SD) & $17.3(8.2)$ & $22.9(8.0)$ & $24.7(8.3)$ & $24.2(8.6)$ & $<0.00 \mathrm{I}$ \\
\hline \multicolumn{6}{|c|}{ COPD impact according to CAT } \\
\hline None, score $<5$ & $36(4.1)$ & $5(2.2)$ & $6(2.4)$ & $8(2.3)$ & $<0.001$ \\
\hline Low, score 5-9 & $106(14.5)$ & $8(3.5)$ & $5(2.0)$ & $7(2.0)$ & \\
\hline Medium, score 10-20 & $332(45.3)$ & $68(29.8)$ & $54(21.3)$ & $96(27.5)$ & \\
\hline High, score $>20$ & $207(28.2)$ & $110(48.2)$ & $125(49.4)$ & $156(44.7)$ & \\
\hline Very high, score $>30$ & $52(7.1)$ & $37(16.2)$ & $63(24.9)$ & $82(23.5)$ & \\
\hline \multicolumn{6}{|l|}{ BODEx index } \\
\hline $0-2$ points & $427(62.7)$ & III (16.3) & $40(5.9)$ & $103(15.1)$ & $<0.00 \mathrm{I}$ \\
\hline $3-4$ points & $182(4 \mid .3)$ & $57(12.9)$ & $82(18.6)$ & $120(27.2)$ & \\
\hline $5-6$ points & $60(25.8)$ & $14(6.0)$ & $86(36.9)$ & $73(3 \mid .3)$ & \\
\hline$\geq 7$ points & $4(8.7)$ & $3(6.5)$ & $23(50.0)$ & $16(34.8)$ & \\
\hline
\end{tabular}

Note: Data expressed as frequencies and percentages in parenthesis unless otherwise stated.

Abbreviations: ACOS, asthma-COPD overlap syndrome; CAT, COPD assessment test; BODEx, body mass index, airflow obstruction, dyspnea, and exacerbations.

the sample provides adequate population coverage and is representative of the current situation in the country.

As far as we are aware, this is the first study of these epidemiological characteristics presenting comprehensive data of the distribution of distinct phenotypes among patients with COPD in Spain. Main findings of the study include the demonstration of differences in the prevalence rates of COPD phenotypes in two specific aspects. First, a comparison of the overall prevalence rates among the four phenotypes across the country revealed higher figures for the non-exacerbator phenotype followed by the exacerbator with chronic bronchitis phenotype, with much lower rates for the exacerbator with emphysema, and ACOS phenotypes. Second, within each phenotype, differences in the prevalence rates across the autonomous communities were observed. Interestingly, the four phenotypes showed a consistent geographic distribution pattern, with the highest rates concentrated in two or three autonomous regions on a background map of somewhat similar rates for the remaining communities. Also, it is noteworthy that the communities with the highest prevalence rates have not been the same for the different phenotypes, possibly reflecting the influence of demographic and socioeconomic characteristics of each particular geographic region. However, with respect to the ACO phenotype, although it is a well-known clinical phenotype, there is no agreement as to how to perform the diagnosis, and therefore, its prevalence may vary according to criteria used for diagnosis. ${ }^{19}$

In our study, the non-exacerbator phenotype was the most common with a prevalence of $46.7 \%$ followed by exacerbator with chronic bronchitis $(22.4 \%)$, exacerbator 
with emphysema (16.4\%), and ACOS (14.5\%). These percentages are similar to $47.5 \%, 29.1 \%, 17.0 \%$, and $6.5 \%$, respectively, found in a cross-sectional sample of 647 patients with COPD reported in the study of Calle Rubio et al, ${ }^{20}$ in which the same GesEPOC guidelines for the definition of the four phenotypes were used. Also, our results are consistent with the distribution of phenotypes found in 4,508 audited clinical records of patients diagnosed with COPD reported in the EPOCONSUL study. ${ }^{21}$ In another small clinical series of 192 patients assessing the utility of the measurement of nitric oxide in exhaled air in the diagnosis of COPD phenotypes, the percentages of distribution of the four phenotypes were also similar. ${ }^{21}$ Our results are also in line with a similar study from Central and Eastern European countries where differences in prevalence among COPD phenotypes were also observed between sites. ${ }^{22}$

Differences in the distribution of COPD phenotypes with respect to gender, age, physician specialty, smoking habit, number of comorbidities, quality of life assessed with CAT, and the BODEx index were all statistically significant. As may be expected, the exacerbator phenotypes both with emphysema and chronic bronchitis were significantly more common in COPD patients with the following characteristics: male gender, older age, active smokers, presence of various comorbidities, and higher CAT and BODEx scores. On the other hand, in relation to the distribution of phenotypes by clinical setting, the non-exacerbator phenotype was most commonly diagnosed by pulmonologists $(58.3 \%)$ as compared to family physicians (31.8\%). These results are similar to those reported in previous studies. ${ }^{19}$ In the CHAIN cohort study, $66 \%$ of the patients visiting pulmonology sites were of non-exacerbator phenotype. ${ }^{19}$ The lower percentage of exacerbators with chronic bronchitis among patients recruited at pulmonology services than in primary care centers $(15.3 \%$ vs $32 \%$ ) might be explained in part by a more intense therapy in patients followed by pulmonology specialists. ${ }^{20}$

Also, it may be speculated that some of these patients are not referred to pneumology services because of the presence or more comorbidities, the management of which is more feasible in the primary care setting. In addition, some of these patients could have been suffering from two moderate exacerbation episodes that were not considered severe enough by the family physician to refer the patients to the pulmonology specialist. The high CAT scores may indicate that patients still have a high impact of the disease despite currently available treatments. Moreover, $58 \%$ of patients had a high degree of dyspnea (grade 2 or higher), which contributes to raise CAT score.
Results of the present study should also be interpreted by taking into account some limitations, particularly the fact that patients were on treatment for which it is unknown whether any phenotype could have been changed at the time of assessment. However, the large sample of COPD patients who attended both in the primary care setting and in specialized pneumology services is representative of health care provided to COPD patients in Spain.

\section{Conclusion}

This study provides evidence of the geographic distribution of COPD phenotypes in Spain and across the autonomous communities of the country. Differences in the prevalence rates of COPD phenotypes among the different autonomous regions have been documented. Mapping the distribution of COPD phenotypes is useful to highlight regional differences as starting point for further comparisons across time. This geographic analysis also provides health-care planners a valuable platform to assess changes in COPD burden at nationwide and regional levels.

\section{Acknowledgments}

The authors thank Marta Pulido, MD, $\mathrm{PhD}$, for editing the manuscript and editorial assistance. This study was funded by Grupo Ferrer, Barcelona, Spain.

\section{Disclosure}

Dr Alcázar-Navarrete reports personal fees from GSK; grants, personal fees, and non-financial support from Novartis $\mathrm{AG}$; personal fees and non-financial support from Boehringer Ingelheim; personal fees and non-financial support from Chiesi; grants, personal fees, and non-financial support from Laboratorios Menarini; personal fees from Gebro; personal fees from Astra-Zeneca, outside the submitted work. Ms Anna Campuzano and Joselín Pérez are full-time employees at Grupo Ferrer Internacional. The authors report no other conflicts of interest in this work.

\section{References}

1. Chapman KR, Mannino DM, Soriano JB, et al. Epidemiology and costs of chronic obstructive pulmonary disease. Eur Respir J. 2006;27(1): 188-207.

2. Mannino DM. Epidemiology and global impact of chronic obstructive pulmonary disease. Semin Respir Crit Care Med. 2005;26(2):204-210.

3. GBD 2016 Disease and Injury Incidence and Prevalence Collaborators. Global, regional, and national incidence, prevalence, and years lived with disability for 328 diseases and injuries for 195 countries, 1990-2016: a systematic analysis for the Global Burden of Disease Study 2016. Lancet. 2017;390(10100):1211-1259. 
4. GBD 2015 DALYs and HALE Collaborators. Global, regional, and national disability-adjusted life-years (DALYs) for 315 diseases and injuries and healthy life expectancy (HALE), 1990-2015: a systematic analysis for the Global Burden of Disease Study 2015. Lancet. 2016;388(10053):1603-1658.

5. Peña V, Miravitlles M, Gabriel R, et al. Geographic variations in prevalence and underdiagnosis of COPD: results of the IBERPOC multicentre epidemiological study. Chest. 2000;118(4):981-989.

6. Miravitlles M, Soriano JB, García-Río F, et al. Prevalence of COPD in Spain: impact of undiagnosed COPD on quality of life and daily life activities. Thorax. 2009;64(10):863-868.

7. Fromer L. Diagnosing and treating COPD: understanding the challenges and finding solutions. Int J Gen Med. 2011;4:729-739.

8. Llordés M, Jaén A, Almagro P, et al. Prevalence, risk factors and diagnostic accuracy of COPD among smokers in primary care. COPD. 2014; 12(4):404-412.

9. Friedlander AL, Lynch D, Dyar LA, Bowler RP. Phenotypes of chronic obstructive pulmonary disease. COPD. 2007;4(4):355-384.

10. Han MK, Agusti A, Calverley PM, et al. Chronic obstructive pulmonary disease phenotypes: the future of COPD. Am J Respir Crit Care Med. 2010;182(5):598-604.

11. Miravitlles M, Calle M, Soler-Cataluña JJ. Clinical phenotypes of COPD: identification, definition and implications for guidelines. Arch Bronconeumol. 2012;48(3):86-98.

12. Zbozinkova Z, Barczyk A, Tkacova R, et al. POPE study: rationale and methodology of a study to phenotype patients with COPD in Central and Eastern Europe. Int J Chron Obstruct Pulmon Dis. 2016;11:611-622.

13. Global strategy for the diagnosis, management and prevention of COPD. Global Initiative for Chronic Obstructive Lung Disease (GOLD); 2014. Available from: http://www.goldcopd.org/. Accessed September 15, 2016.
14. Miravitlles M, Soler-Cataluña JJ, Calle M, et al. Spanish COPD Guidelines (GesEPOC): pharmacological treatment of stable COPD. Spanish society of pulmonology and thoracic surgery. Arch Bronconeumol. 2012;48(7):247-257.

15. Mahler DA, Wells CK. Evaluation of clinical methods for rating dyspnea. Chest. 1988;93(3):580-586.

16. Soler-Cataluña JJ, Martínez-García MA, Sánchez Sánchez L, Perpiñá Tordera M, Román Sánchez P. Severe exacerbations and BODE index: two independent risk factors for death in male COPD patients. Respir Med. 2009;103(5):692-699.

17. Jones PW, Harding G, Berry P, et al. Development and first validation of the COPD assessment test. Eur Respir J. 2009;34(3):648-654.

18. Soler-Cataluña JJ, Cosío B, Izquierdo JL, et al. Consensus document on the overlap phenotype COPD-asthma in COPD. Arch Bronconeumol. 2012;48(9):331-337.

19. Cosío BG, Soriano JB, López-Campos JL, et al. Defining the asthmaCOPD overlap syndrome in a COPD cohort. Chest. 2016;149(1):45-52.

20. Calle Rubio M, Casamor R, Miravtlles M. Identification and distribution of COPD phenotypes in clinical practice according to Spanish COPD guidelines: the FENEPOC study. Int J Chron Obstruct Pulmon Dis. 2017;12:2373-2383.

21. Alcázar-Navarrete B, Romero-Palacios PJ, Ruiz-Sancho A, RuizRodriguez O. Diagnostic performance of the measurement of nitric oxide in exhaled air in the diagnosis of COPD phenotypes. Nitric Oxide. 2016;54:67-72.

22. Koblizek V, Milenkovic B, Barczyk A, et al. Phenotypes of COPD patients with a smoking history in Central and Eastern Europe: the POPE Study. Eur Respir J. 2017;49:1601446.
International Journal of COPD

\section{Publish your work in this journal}

The International Journal of COPD is an international, peer-reviewed journal of therapeutics and pharmacology focusing on concise rapid reporting of clinical studies and reviews in COPD. Special focus is given to the pathophysiological processes underlying the disease, intervention programs, patient focused education, and self management protocols.

\section{Dovepress}

This journal is indexed on PubMed Central, MedLine and CAS. The manuscript management system is completely online and includes a very quick and fair peer-review system, which is all easy to use. Visit http://www.dovepress.com/testimonials.php to read real quotes from published authors. 